\title{
Navigating Cognitive Innovation
}

\author{
Michael S. Kristensen1,2* (D) , Frank Loesche1,2 (D) , \& Diego S. Maranan1,3 \\ ${ }^{1}$ CogNovo \\ 2 Cognition Institute, Plymouth University, UK \\ 3 University of the Philippines Open University \\ *Corresponding author Michael.Sonne.Kristensen@CogNovo.eu
}

Received 12 May 2017; accepted 26 September 2017; published 21 November 2017.

\begin{abstract}
This paper revisits the concept of Cognitive Innovation with the aim of helping newcomers appreciate its (intended) demarcating purpose and relevance to the wider literature on cognition and creativity in the humanities, arts, and sciences. Particular emphasis is paid to discussion of the pitfalls of sense-making and the concept's affordance. The main argument presented is that proponents of the concept face the dilemma of seeking to demonstrate its transdisciplinary nature and applicability vis-a-vis retaining its semantic distinctness. Proceeding from a classification of Cognitive Innovation as a dispositional construct, we discuss how it feeds into existing research approaches and opens up new sensibilities in related areas. The perspectives of temporality, interdisciplinary balancing, technology, and metatheories are proposed as promising areas for future elaboration of the function of Cognitive Innovation.
\end{abstract}

Keywords: concept analysis; creativity; interdisciplinarity; metatheory; temporality.

\section{Introduction}

In her seminal paper on concept analysis, Rodgers argues that intellectual progression is greatly impaired when definitions and attributes of fundamental concepts are not made clear: "[Q]uestions regarding vague or ambiguous concepts are met with confused responses that are dependent upon individual and often ad hoc interpretations" (Rodgers, 1989, p. 330). Conceptual unclarity characterizes several research areas that have become tantalizing in cognitive science within the last decades, including creativity, consciousness, cognition and play. Research that proposes 
measures of creativity or attempts to determine neural correlates of creativity is often criticized not on the basis of its methodological rigor, but on the basis of its claim to represent the concept of creativity. At the same time this might also be the root of disagreement between different lines of research.

Lack of clarity regarding the concept of creativity has been a recurrent theme within CogNovo's ${ }^{1}$ network of principal investigators, PhD students, affiliates, and partners, where presentations on creativity have often extended into dead-end discussions about fundamental ontological and epistemological questions. In order to overcome these discursive impasses, Denham and colleagues proposed the notion of Cognitive Innovation to help position (or perhaps displace) creativity. In this paper, we draw attention to the notion of Cognitive Innovation as we understand Denham (2014), Gummerum and Denham (2014) and Denham and Punt (2017), collectively referred to as "Denham and colleagues."

To help tighten the grip of the concept's unique affordance, we examine a series of issues regarding interpretation and comprehension of the depictions by which the concept comes into expression. Our aim is twofold: first, to help newcomers to the concept appreciate its (intended) demarcating purpose; second, to suggest new approaches to interdisciplinary research on cognition.

\section{Cognitive Innovation as a Neologism}

The notion of Cognitive Innovation was coined long before the recent rendering by Denham and colleagues, when Acker and McReynolds (1965) introduced the Obscure Figures Test as a measurement of Cognitive Innovation. Their paper references a talk at the annual convention of the American Psychology Association as the source of the term, but the available proceedings do not mention it at all (McReynolds, 1964). Presumably the term was discussed during the talk and summarized in Acker and McReynolds (1965):

It is conceived that in the course of his commerce with his ${ }^{2}$ environment, an individual builds up an over-all cognitive structure which for him represents the nature of reality and in terms of which input data should be processed. This over-all cognitive structure can be assumed to undergo certain changes over time. The processes whereby these changes are brought about are what is meant by "cognitive innovation," i.e., innovation or the introduction of newness into the cognitive structure. (p. 851)

\footnotetext{
${ }^{1}$ CogNovo started as a doctoral training program at Plymouth University, jointly funded by the EU through the Marie Curie Actions and Plymouth University. For an overview of the CogNovo program (https://CogNovo.eu) and its twenty-four research projects, see Maranan, Loesche, and Denham (2015).

${ }^{2}$ For clarification: even though only male performance is discussed, females and males participated in the study. Presumably the assumption and results apply to both genders, even though the wording suggests otherwise.
} 
The cognitive structure mentioned here resembles to some extent imagery or mental representation and individual knowledge. The manipulation of internal structures towards something novel is what Acker and McReynolds (1965) address with their use of the term Cognitive Innovation. Denham and colleagues also mention such manipulation as a key property in their articulation of the concept. Interestingly this exhibits some overlap between the two uses of the term, without explicit reference.

In perhaps the most succinct linguistic definition available from their contributions, Denham articulates the concept of Cognitive Innovation as "a recursive process in which an individual probes its boundaries to seek out new knowledge, selects promising avenues for more extensive exploitation, and synthesizes what it learns within its growing body of knowledge" (Denham \& Punt, 2017, supplement, p. 4). Denham refers to Cognitive Innovation as a generic and recursive function manipulating not just the imagery (and other explicit knowledge), but also the individual's set of internal mental processes and the Cognitive Innovation function itself. The sum of sensory inputs is the third distinct parameter feeding into the Cognitive Innovation function. In its functional form, Cognitive Innovation is presented as

$$
F_{t+d t}, x_{t+d t} \Leftarrow F_{t}\left(F_{t}, x_{t}, s_{t}\right)
$$

where

$F$ represents the mental processing of an individual, and the set of things it knows about, . . . F $F_{t}$ represents all internal (mental) processes, is the set of ideas, facts, words, and so on that are known by the individual and can be exchanged with others, $s_{t}$ are things in the world perceptually accessible to the individual and $t$ is an index of time. (Denham \& Punt, 2017, supplement, p. 5)

\section{Cognitive Innovation as a Dispositional Concept}

Whereas Denham and colleagues seem to have a strong idea about the essence of Cognitive Innovation, we draw attention to the question of how to make sense across the vast range of disciplines that are engaged with cognition and innovation. Lack of familiarity with the concept poses at least two pitfalls in terms of sense-making.

First, the reallocation of meaning to a compound term which makes use of omnipresent words with rich historical semiotic loads requires the term to be freed from unintended meanings. Familiarity with its constituting terms of cognition and innovation may misleadingly activate interpretations that combine unintended attributes of both. Cognitive science forms its own research domain, including a set of disciplines at the intersection between neuroscience, anthropology, artificial intelligence, linguistics, philosophy, and psychology (see Thagard, 2005, p. X [sic]). Innovation appears to be used within social sciences and economic and engineering 
literature, with an emphasis on multi- and interdisciplinary work (see Crossan \& Apaydin, 2009; Fagerberg, Fosaas, \& Sapprasert, 2012). As a result, innovation has a number of definitions across and within different disciplines, often related to the "implementation of creative ideas" (Amabile, 1988, p. 126) and echoing two dimensions also used for the definition of creativity on individual levels of novelty and usefulness (see Runco \& Jaeger, 2012; Stein, 1953), but typically measured on an organizational level (Sawyer \& Bunderson, 2013, p. 14). In short, we note that each of the constituting elements of Cognitive Innovation are very rich and semantically overloaded. As opposed to the blank slate approach of inventing an artificial word to describe the concept, cognition and innovation-to stay within the metaphor-have chalk scribbles dense enough to provide some colored but almost indistinguishable background. At the same time, this approach situates Cognitive Innovation in approximation to metatheories, involving humans and human behavior.

A second (general) pitfall of sense-making is that one thing is understood in terms of something else, be it an existing conceptual framework, terminology, or historical or cultural situatedness. Gadamer's (1960) notion of fusion of horizons (Horizontverschmelzung) eloquently captures the inevitable compromise that takes place during any text comprehension: two "horizons," i.e., scopes of insight restrained by "historically effected consciousness," are fused during the interpretative act-the horizon of the text and the one of the reader. Thus, the same description of Cognitive Innovation will most likely be understood quite differently by an expert on, say, Cognitive Flexibility Theory (e.g., Spiro, Coulson, Feitovich, \& Anderson, 1988) than by an expert on epistemology (e.g., Archer, 1988). Both topics share similarities with Denham's description of Cognitive Innovation, but respectively emphasize the different aspects of learning and knowledge production. While aspects and insights from such related domains are commensurable with the description of Cognitive Innovation, it is impossible to determine in an absolute sense whether such aspects are intrinsic features of Cognitive Innovation. Denham may say they are, or are not, and someone else may say the opposite. Hereby a challenge regarding the conceptual clarity of Cognitive Innovation emerges: Denham's definition of the concept-a recursive process of exploration, exploitation, and synthesis-is expressed at a very high level of abstraction that is easily translatable or applicable to numerous domains and contexts. While this genericity may be embraced and leveraged, as exemplified by all the writings of Denham and colleagues, the question of the concept's boundary marking is left unresolved (except for the distinction between creativity and Cognitive Innovation). ${ }^{3}$ Whether or not this semantic fluidity is a problem depends on the ontological underpinnings of the concept.

\footnotetext{
${ }^{3}$ Denham and Punt, however, seem to be aware of this contingent imposing of meaning onto the concept in acknowledging that what they are tackling "is, and also is not, necessarily the same thing" (Denham \& Punt, 2017, p. 185).
} 
Historically, concepts have been thought of as belonging to one of two categories (Rodgers, 1989): "Entity views" treat a concept as a clearly demarcated and stable "thing" with a rigid set of necessary and sufficient conditions. The essence and truth value of a concept can therefore be approached positively through a reductionist approach and should not be examined relative to some context. "Dispositional views," on the other hand, treat concepts as habits or behavioral potentials. In contrast to a fixed and reductionist approach, they acknowledge dynamic formation of concepts through individuals' interpretation and utilization as a sine qua non condition. We argue that the concept of Cognitive Innovation is a dispositional construct. This is perhaps most clearly expressed in the paper by Denham and Punt (2017), which articulates the concept on the basis of two distinct mindsets influenced by the domains of computational neuroscience and media archeology, respectively. Whereas this dual perspective arguably supports their intention to promote Cognitive Innovation as a focus for collaboration between the sciences, arts, and humanities, the format of the paper-two self-standing essays "in which the contributing specialisms retain their academic and methodological distinction and voice" (Denham \& Punt, 2017, p. 184) -does not promote fusion of disciplinary horizons by example. Bearing this point in mind, the "bridge" from which Denham and Punt (2017) look at Cognitive Innovation (as indicated by the paper's title) is probably better understood as a nautical metaphor (i.e., the platform from which a ship is commanded) than as a construction that connects existing platforms across a gap. A pertinent question posed by this interpretation is: Where is the ship heading?

\section{Charting New Territories in Cognitive Innovation}

If we proceed from the assumption that Cognitive Innovation is a dispositional construct, we can begin to envisage how the concept feeds into existing research approaches and opens up new sensibilities. The following three strands of thought follow from our contemplation of the notational form of the functional definition of Cognitive Innovation.

\section{Emphasizing the Temporality of Cognitive Innovation and Creativity}

In cognitive sciences, creativity is assumed to be a stable trait that can be measured without changing it. Both the functional description of creativity by Denham and colleagues and their characterization of Cognitive Innovation instead emphasize their malleability to influences over time. Even in their notation, time might be overlooked as a small subscript to the parameters and results, but it is a subscript to every single parameter. Indeed time, it could be argued, should be more explicitly addressed in the study of creativity as it emerges from Cognitive Innovation. 
The effect of task-specific training has been shown for divergent and convergent thinking (Scott, Leritz, \& Mumford, 2004), as well as insightful tasks (Weisberg, 2014). This alteration of internal knowledge, as represented by $x t$ in the Cognitive Innovation function, changes with repeated exposure and therefore time. Based on this empirical and anecdotal underpinning it is no surprise that time plays an important role in many theoretical models of creativity, such as the temporal stages mentioned by Wallas (1926) to Csikszentmihalyi (1988), and basically any idea that taps into the second "P" (Process) from Rhodes' (1961) "four Ps of creativity" model, which uses time as an independent variable.

Following up on this theoretical stance, it remains unclear how much the recursion of perceived time (for example, through Earth's rotations around the Sun and itself) or technologically and culturally constructed time (rotations of minute hands on clocks, "the same" bus every 7 minutes) itself is intrinsically reflected in the functional description by Denham and colleagues. Future discussions might want to address the effect chrono-biological or chrono-technological processes have on the recursion of Cognitive Innovation.

A temporal perspective can also be used to illustrate the difference between Cognitive Innovation and creativity. Denham and colleagues characterize creativity as an exaptation of Cognitive Innovation and appear to suggest that creativity is a contemporary and socially grounded expression of what is ultimately Cognitive Innovation. ${ }^{4}$ The distinction can be perceived with a thought experiment: What was creativity (or what did people think about it) 10 years ago? Probably it was similar to what we think now. What about 100 years ago, when the word "creativity" first emerged in Western languages? What about 6,500 years ago, when the wheel was invented? What about 525 million years ago, when the first vertebrates emerged? 525 million years ago, creativity was probably "non-existent," whereas cognitive innovation probably did exist.

\footnotetext{
${ }^{4}$ Part of what distinguishes creativity from Cognitive Innovation is that the notion and valuation of creativity (and what constitutes a creative product, process, or person) is contingent on its environment in all its social, cultural, technological, and political dimensions. For instance, it has been suggested that social risk-taking is associated with creativity (Tyagi, Hanoch, Hall, Runco, \& Denham, 2017); that is to say, what or who is creative is not necessarily considered socially acceptable. A second distinction of Cognitive Innovation from creativity - potentially also a consequence of the involvement of multiple agents-is the application or at least applicability of the resulting products. The formula Cognitive Innovation = creativity + communication + application is oversimplifying the idea of Cognitive Innovation as an "endless cycle of exploration, exploitation, and explanation" (see Gummerum \& Denham, 2014, p. 586), but emphasizes the distinction to creativity nevertheless.
} 


\section{Decomposability, Balancing Interdisciplinarity, and Technology}

The functional definition of Cognitive Innovation states that it is recursively constituted of an individual's mental processes $(F)$, their existing knowledge $(x)$, and properties of the perceptually accessible world ( $s$ ). Denham and Punt (2017) further suggest creativity is constituted not only by the terms of the Cognitive Innovation function, but additionally by the knowledge $(y)$ and cultural and societal processes $(G)$ of the community (Denham \& Punt, 2017, supplement, p. 10). We propose that the decomposability of Cognitive Innovation and creativity in such particular terms affords strategies for evaluating and advancing interdisciplinary research programs such as CogNovo.

First, it suggests that a research group studying Cognitive Innovation and creativity would best be served by a disciplinary mix that included not only cognitive neuroscience and psychology to cover terms $F$ and $x$, but also cultural anthropology and political sociology (which were absent in CogNovo), perhaps with an emphasis on ethnography as a methodology. This complement of disciplines more fully corresponds to the components of the functions.

Second, it calls for reflection on the role that computational sciences and media studies play in the research agenda of an interdisciplinary research group studying human creativity. Why should computation, media, and technology matter in this field? In the creativity function, where do things like hammers, telescopes and mobile phones fit in? Strictly speaking, they are simply part of the perceptible world, $s$, yet they seem to be more significant than that. We suggest that technology (in the sense of apparatuses, equipment, and tools) might be considered to constitute a special aspect not only of the material, perceptible world $(s)$, but also of societies' ways of thinking and doing $(G)$. Describing the function of contemporary technology, Punt (Denham \& Punt, 2017, p. 185) points out that technology serves to supplement the human body, either by "alleviat[ing] the hardships of nature through muscular amplification" (particularly in the past), whereas contemporary technology (also) extends the "limitations of the sensory range" of the human organism. Indeed, technology can, as McLuhan (1964) argues, be an "extension of ourselves" in that it extends the cognitive system as much as it can extend the body (Brey, 2000). Technology can play an active role both in perceiving the world differently and also in transforming it. We thus argue that technology deserves to be set aside as a special term in the creativity function. Hence, the creativity function

$$
F_{t+d t}, x_{t+d t}, G_{t+d t}, y_{t+d t}, s_{t+d t} \Leftarrow F_{t}\left(F_{t}, x_{t}, G_{t}, y_{t}, s_{t}\right)
$$

might be more completely described as

$$
F_{t+d t}, x_{t+d t}, G_{t+d t}, y_{t+d t}, s_{t+d t}, T_{t+d t} \Leftarrow F_{t}\left(F_{t}, x_{t}, G_{t}, y_{t}, s_{t}, T_{t}\right)
$$

where $T$ stands for technology—the apparatuses, devices, and mechanisms that extend the body and brain, and thus arguably extends (or at the very least mediates) 
human agency (Latour, 1994). That is to say, the recursive, functional form of Cognitive Innovation and creativity facilitates an extended description of cognition that is much in line with theories of The Extended Mind (e.g., Clark \& Chalmers, 1998). This transcends the focus on intra-cranial processes, which historically have been the object of cognitive studies.

\section{Cognitive Innovation and Metatheory}

The existing articulations of Cognitive Innovation do not explicitly mention any particular philosophical anchorage, nor do they claim to pertain to any context, historical era or culture. In this regard, the concept shares fundamental features with metatheories. One example of a metatheoretical framework with particular strong affinities to Cognitive Innovation is Clare Graves' Emergent, Cyclical, Double-Helix Model of Adult BioPsychoSocial Systems Development (e.g., Graves, 1974). Graves' lifelong project was to study no less than the developmental path of human nature. In the 1950s he began to collect anthropological and psychological data without having any hypothesis, in an approach similar to what was later formalized as Grounded Theory by Glaser and Strauss (1967). The culmination of his work was the proposal of a pattern and direction in the path of human development in the form of a framework that integrates various theories of human development, e.g., Maslow's (1943) hierarchy of needs, and Dawkins' (1976) idea of memes. On the basis of data collected over a period of more than 30 years, Graves proposed seven developmental levels of being or existence in the world that occur in a predictable successive order. ${ }^{5}$

Graves' work, we propose, is relevant for Cognitive Innovation as it demonstrates traces of recursion at work and also demonstrates the link to societal processes and community knowledge. It is a rich qualitative account of what Cognitive Innovationa shadowless structural description-leaves behind, so to speak. Graves' model shares with the model of Cognitive Innovation the aim to account for development from more primitive levels or states to more sophisticated levels or states. Graves' model does this by suggesting a particular direction in the spiral of development of human nature, whereas the model of Cognitive Innovation suggests bootstrapping mechanisms by which development takes place. Whether the latter qualifies for the label of a metatheory is debatable, but at least Cognitive Innovation lends itself as a useful supplement to enhancing self-reflexivity in metatheoretical frameworks like Graves' in a concise way.

\footnotetext{
${ }^{5}$ Graves' work (particularly his taxonomy of developmental levels) has been popularized by Beck and Cowan's (2005) work on Spiral Dynamics and Ken Wilber's (2000) work on Integral Theory.
} 


\section{Conclusion}

The pragmatic value of the concept of Cognitive Innovation to the academic discourse on creativity (and other fields) will stand its test in years to come. It is tempting, both to proponents and reviewers of the concept, to elaborate on possible meanings suggested by the semantic load of its two constituting terms, not least because many concepts in the history of cognitive studies appear to be closely related, named similarly, or both. However, subsuming too many principles under the concept-a likely consequence of opening it up to fit existing discourses of various disciplines-comes with the risk of diluting its semantic span. For this reason, we have suggested that Cognitive Innovation ought to be thought of more in terms of a metatheoretical framework than as a concept. While increasing the accessibility of Cognitive Innovation to a wide audience is in line with Denham and Punt's aspiration to have it provide "a theoretical and practical platform from which to explore disciplinary differences in our understanding of creativity" (Denham \& Punt, 2017, p. 184), it is potentially confusing to propose what seems to be a semantic chameleon as a conceptual demarcation from creativity. In addition to pointing out this dilemma (without attempting to solve it), we have highlighted a few aspects of sense-making and affordances of the concept that we think future investigations should examine in more detail.

While Denham and Punt (2017) do not directly propose a method to integrate their different disciplinary specialisms by which they approach and discuss Cognitive Innovation, their individual horizons clearly intersect and seem to be within the reach of integration or fusion. It seems therefore as if the challenge of promoting Cognitive Innovation as a research object lies not so much in the description of the concept, but rather in how to study and write about it in a transdisciplinary manner. We have outlined a few ideas on temporality, interdisciplinary balancing and metatheories that we believe are important to consider in more detail in future enquiries and developments of Cognitive Innovation to navigate analytical operations in the muddy waters of conceptual territory.

\section{Acknowledgements}

We thank Sue Denham and Witold Wachowski for their constructive feedback in both writing and discussion. This research was sponsored by the People Programme (Marie Curie Actions) of the European Union's Seventh Framework Programme FP7/2007-2013/ under the REA grant agreement no. FP7-PEOPLE-2013-ITN604764 . 


\section{References}

Acker, M., \& McReynolds, P. (1965). The obscure figures test: An instrument for measuring "cognitive innovation." Perceptual and Motor Skills, 21(3), 815-821. doi:10.2466/pms.1965.21.3.815

Amabile, T. M. (1988). A model of creativity and innovation in organizations. In B. M. Staw \& L. L. Cummings (Eds.), Research in organizational behavior (Vol. 10, pp. 123-167). Greenwich, CT: JAI Press.

Archer, S. (1988). Qualitative research and the epistemological problems of the management disciplines. In A. M. Pettigrew (Ed.), Competitiveness and the management process (pp. 265-302). Oxford, UK: Wiley-Blackwell.

Beck, D. E., \& Cowan, C. (2005). Spiral dynamics: Mastering values, leadership, and change. Hoboken, NJ: John Wiley \& Sons.

Brey, P. A. (2000). Theories of technology as extension of human faculties. In C. Mitcham, Research in philosophy and technology: Volume 19, Metaphysics, epistemology and technology (pp. 59-78). Bingley, UK: Emerald.

Christensen, P. R., Guilford, J. P., \& Wilson, R. C. (1957). Relations of creative responses to working time and instructions. Journal of Experimental Psychology, 53(2). doi:10.1037/h0045461

Clark, A., \& Chalmers, D. (1998). The extended mind. Analysis, 58(1), 7-19. doi:10.1093/analys/58.1.7

Crossan, M. M., \& Apaydin, M. (2009). A multi-dimensional framework of organizational innovation: A systematic review of the literature. Journal of Management Studies, 47(6), 1154-1191. doi:10.1111/j.1467-6486.2009.00880.x

Csikszentmihalyi, M. (1988). Motivation and creativity: Towards a synthesis of structural and energistic approaches to cognition. New Ideas in Psychology, 6(2), 159-176. doi:10.1016/0732-118X(88)90001-3

Dawkins, R. (1976). The selfish gene. New York, NY: Oxford University Press.

Denham, S. L. (2014). Marie meets leonardo: A perfect match? Leonardo, 47(3), 202. doi:10.1162/LEON_e_00707

Denham, S. L., \& Punt, M. (2017). Abstract of "Cognitive innovation: A view from the bridge." Leonardo, 50(2), 184-185. doi:10.1162/LEON_a_01386

Fagerberg, J., Fosaas, M., \& Sapprasert, K. (2012). Innovation: Exploring the knowledge base. Research Policy, 41(7), 1132-1153. doi:10.1016/j.respol.2012.03.008

Gadamer, H.-G. (1960). Wahrheit und methode: Grundzüge einer philosophischen hermeneutik. Tübingen: Mohr Siebeck.

Glaser, B. G., \& Strauss, A. L. (1967). The discovery of grounded theory: Strategies for qualitative inquiry. Chicago, IL: Aldin.

Graves, C. W. (1974). Human nature prepares for a momentum leap. The Futurist, 1974, 72-87.

Gummerum, M., \& Denham, S. L. (2014). Cognitive innovation: From cell to society. Europe's Journal of Psychology, 10(4), 586-588. doi:10.5964/ejop.v10i4.879 
Latour, B. (1994). On technical mediation. Common Knowledge, 3(2), 29-64.

Maranan, D. S., Loesche, F., \& Denham, S. L. (2015). CogNovo: Cognitive innovation for technological, artistic, and social domains. In Proceedings of the 21st International Symposium on Electronic Arts. Retrieved from http://hdl.handle.net/10026.1/5076

Maslow, A. H. (1943). A theory of human motivation. Psychological Review, 50(4), 370-396.

McLuhan, M. (1964). Understanding media: The extensions of man. New York, NY: New American Library.

McReynolds, P. (1964). Toward a theory of fun. American Psychologist, 19, 551-552.

Rhodes, M. (1961). An analysis of creativity. The Phi Delta Kappan, 42(7), 305-301.

Rodgers, B. L. (1989). Concepts, analysis and the development of nursing knowledge: The evolutionary cycle. Journal of Advanced Nursing, 14(4), 330-335. doi:10.1111/j.13652648.1989.tb03420.x

Runco, M. A., \& Jaeger, G. J. (2012). The standard definition of creativity. Creativity Research Journal, 24(1), 92-96. doi:10.1080/10400419.2012.650092

Sawyer, K., \& Bunderson, S. (2013). Innovation: A review of research in organizational behavior. In A. Thakor (Ed.) Innovation and growth: What do we know? (pp. 13-55). Hackensack, NJ: World Scientific. doi:10.1142/9789814343558_0002

Scott, G., Leritz, L. E., \& Mumford, M. D. (2004). Types of creativity training: Approaches and their effectiveness. The Journal of Creative Behavior, 38(3), 149-179. doi:10.1002/j.21626057.2004.tb01238.x

Spiro, R. J., Coulson, R. L., Feitovich, P. J., \& Anderson, D. K. (1988). Cognitive flexibility theory: Advanced knowledge acquisition in ill-structured domains (Technical report No. 441). Campaign: University of Illinois at Urbana-Champaign, Center for the Study of Reading.

Stein, M. I. (1953). Creativity and culture. The Journal of Psychology, 36(2), 311-322. doi:10.1080/00223980.1953.9712897

Thagard, P. (2005). Mind: Introduction to cognitive science ( $2^{\text {nd }}$ ed.). Cambridge, MA: MIT Press.

Tyagi, V., Hanoch, Y., Hall, S. D., Runco, M., \& Denham, S. L. (2017). The risky side of creativity: Domain specific risk taking in creative individuals. Frontiers in Psychology, 8. doi:10.3389/fpsyg.2017.00145

Wallas, G. (1926). The art of thought. London, UK: Jonathan Cape.

Weisberg, R. W. (2014). Toward an integrated theory of insight in problem solving. Thinking \& Reasoning, 21(1), 5-39. doi:10.1080/13546783.2014.886625

Wilber, K. (2000). A theory of everything: An integral vision for business, politics, science, and spirituality. Boston, MA: Shambhala. 